\section{ALTERAÇÕES NA EPIGENÉTICA DO SISTEMA OCITOCINÉRGICO EM RESPOSTA AO CUIDADO MATERNO NEGLIGENTE}

\author{
EPIGENETIC CHANGES IN THE OXYTOCINERGIC SYSTEM \\ IN RESPONSE TO NEGLIGENT MATERNAL CARE
}

\author{
Marcelo da Silva Mendes', Virgínia Meneghini Lazzari
}

Clin Biomed Res. 2019;39(4):333-340

1 Centro Universitário Ritter dos Reis (UniRitter). Porto Alegre, RS, Brasil.

Autor correspondente:

Virgínia Meneghini Lazzari vivimeneghini@gmail.com Centro Universitário Ritter dos Reis (UniRitter)

Rua Orfanotrófio, 555.

90840-440, Porto Alegre, RS, Brasil. que o cuidado materno negligente é um fator de risco para o desenvolvimento de transtornos mentais, principalmente os que incluem sintomas de desordem social. A ocitocina, por agir como uma potente mediadora das interações sociais, confiança e controle da ansiedade, parece ter papel fundamental neste contexto. A notória transgeracionalidade dos transtornos encontrados em proles de mães negligentes parece estar envolvida com mecanismos epigenéticos que inativam genes específicos do sistema ocitocinérgico no sistema nervoso central.

Palavras-chave: Comportamentos sociais; ocitocina; metilação; transtornos mentais

\section{ABSTRACT}

Negligent maternal care, lack of affection and difficulty in social interaction are related to a neurophysiological imbalance in oxytocin levels, an important modulator of social behaviors. In humans there are known links between prenatal and perinatal stress and psychiatric and developmental disorders. This study aimed to review the concept of epigenetics with a focus on the long-term effect of negligent maternal care and its relationship to changes in the oxytocinergic system, based on animal and human studies. A narrative review of the literature was conducted using studies from June 2017 to January 2019 available in the PUBMED database, focusing on qualitative results of epigenetic relationships with child neglect, psychiatric diseases and oxytocinergic system. These studies demonstrate that negligent maternal care is a risk factor for the development of mental disorders, especially those that include symptoms of social disorder. Oxytocin, as a neurohormone that acts as a potent mediator of social interactions, confidence and anxiety control, seems to play a fundamental role in this context. The notorious transgenerationality of the disorders found in the offspring of negligent mothers seems to be due to epigenetic mechanisms that inactivate specific genes of the oxytocinergic system in the central nervous system.

Keywords: Social behaviors; oxytocin; methylation; mental disorders 
Muito além de somente estimular a lactação e promover as contrações uterinas, a ocitocina (OT), ligada em receptores no cérebro, desencadeia uma importante resposta de modulação do comportamento afetivo, do vínculo mãe-bebê, prazer sexual, incluindo o orgasmo, no reconhecimento social e na ansiedade ${ }^{1,2}$.

Em seres humanos, existem ligações conhecidas entre o estresse pré-natal e perinatal a uma variedade de transtornos psiquiátricos e de desenvolvimento, incluindo depressão, esquizofrenia, distúrbios do espectro autista, transtorno bipolar, distúrbio de estresse pós-traumático, transtornos de ansiedade $e$ distúrbios do uso de substâncias ${ }^{3,4}$. Diversos estudos sugerem que a tendência transgeracional destes transtornos advém da remodelação epigenética. Crianças negligenciadas e/ou abusadas tendem a transferir esse comportamento aos filhos, tornandose adultos abusadores e/ou negligenciadores ${ }^{5,6}$.

Estudos prévios demonstram que cuidado materno negligente, a falta de afeto e a dificuldade de interagir socialmente estão relacionadas com o desequilíbrio neurofisiológico do sistema ocitocinérgico ${ }^{7,8}$. Em macacos rhesus, a criação não maternal (afastamento da mãe 48 horas após o nascimento e criação por cuidadores) foi associada a níveis reduzidos de OT do líquido cefalorraquidiano (LCR) nos primeiros 3 anos de vida ${ }^{9}$. Em um trabalho prévio conduzido com mulheres que relataram negligência emocional na infância, também foram encontrados níveis significativamente mais baixos de OT no LCR. Já mulheres cuja exposição à adversidade na infância se deu na forma de negligência física, as alterações nos níveis de OT no LCR foram menos pronunciadas. Além disso, as concentrações de OT foram inversamente correlacionadas com os escores de negligência emocional no Questionário de Traumas Infantis ${ }^{10}$.

A compreensão do modo como os mecanismos biológicos estão correlacionados com o comportamento presume que futuramente possamos oferecer suporte e intervenções que previnam o desenvolvimento de psicopatologias. Sendo assim, esse trabalho busca revisar o conceito de epigenética com foco no efeito a longo prazo do cuidado materno negligente e sua relação com alterações do sistema ocitocinérgico, baseado em estudos em animais e humanos.

\section{A EPIGENÉTICA}

Até poucas décadas atrás, o genoma era conhecido por ser uma estrutura passiva que somente orientava o desenvolvimento do organismo. Porém, as observações de que embora as diferentes células de um organismo tenham a mesma sequência genética, mas com padrões de expressão discrepantes, cunharam a definição do conceito epigenético. A epigenética estuda os mecanismos sensíveis ao ambiente que causam alterações fenotípicas aos seus descendentes ${ }^{11}$.

O epigenoma influencia a atividade e a velocidade da expressão gênica, transformando de forma reversível e herdável o funcionamento do genoma. Diferentemente do genoma em si, que de forma geral é o mesmo em diferentes tipos de células de um organismo, o epigenoma é dinâmico e varia de célula para célula, interferindo diretamente sobre a expressão sem remodelar a sequência de DNA ${ }^{12}$. Estas alterações epigenéticas se dão por exposições ambientais que ativarão ou desativarão genes, interferindo no metabolismo e no comportamento, como uma espécie de adaptação em resposta ao ambiente que começa ainda na vida uterina ${ }^{13}$. Embora variações genéticas como os SNPs, mesmo estando em regiões não codificantes, influenciem a expressão de genes distantes ${ }^{14}$, de modo geral, as características que distinguem a epigenética dos mecanismos genéticos convencionais são a habilidade de agir em distâncias não esperadas maiores do que um único gene, a reversibilidade e os efeitos de posicionamento ${ }^{15}$.

As alterações nas histonas e o padrão de metilação do DNA são os principais mecanismos de modificação epigenética ${ }^{12}$. Esses mecanismos alteram a acessibilidade das enzimas envolvidas na transcrição à cromatina, pelas modificações no DNA e pelos rearranjos dos nucleossomos ${ }^{15}$. De fato, essas modificações regulam a função da cromatina modulando a expressão gênica, impedindo ou facilitando o acesso da maquinaria de transcrição aos genes, e por outro lado, podem permitir a acessibilidade ao genoma de mecanismos de reparação e replicação ${ }^{16}$.

\section{Metilação de DNA}

A metilação é um padrão de regulação que promove a ativação ou o silenciamento da expressão de determinados genes através da intervenção de enzimas chamadas DNA-metiltransferases (DNMT). Estas enzimas reconhecem as regiões promotoras de genes ativos, principalmente sítios ricos em dinucleotídeos CpG (Citosina-fosfato-Guanina) hemimetilados, mas também em locais não $\mathrm{CpG}$ $(\mathrm{CpA}, \mathrm{CpT} \text { e } \mathrm{CpC})^{17}$. A metilação é um processo de catalização e transferência do grupo metil $\left(\mathrm{CH}_{3}\right)$ no carbono $5 \mathrm{~S}$-adenosyl-L-metionina na base Citosina (5-metil-citosina) do DNA ${ }^{18}$. Quando o DNAé metilado ocorre o recrutamento de proteínas e complexos co-repressores como as histonas-desacetilases (HDACs), que promovem a compactação da cromatina, alterando a expressão genética ${ }^{19}$.

Existem três tipos de DNMTs com atividade conhecida sobre o DNA, sendo a DNMT1, DNMT3A e DNMT3B. Enquanto as DNMT 3A e 3B são atuantes principalmente durante os processos de diferenciação celular de células embrionárias atuando 
na chamada metilação de novo, ou seja, realizam as metilações necessárias para a diferenciação celular ou as novas metilações que ocorrem como uma adaptação ao ambiente ${ }^{20}$, a DNMT1 é responsável pela manutenção da metilação celular ${ }^{21}$. Portanto, usando como exemplo as células pancreáticas, no processo de diferenciação celular, no que the confere a especificidade das suas funções e menos gasto energético, as DNMTs 3A e 3B farão a nova metilação, seja no princípio das diferenciações celulares embrionárias como também na primeira metilação posterior induzida por fatores ambientais, como exemplo da diminuição da transcrição do gene do GLUT4 em resposta ao ambiente, como ocorre na diabetes Melitus tipo 2. Já as DNMT1 terão como função a transferência e manutenção deste padrão de metilação para as células filhas. Assim, podemos dizer que as DNMTs 3A e 3B tem maior relação com o ambiente e são as pioneiras em metilar genes específicos em resposta ao ambiente e as DNMTs 1 seguirão transferindo para as células descendentes o padrão de metilação já estabelecido anteriormente pelas DNMTs $3 \mathrm{~A}$ e $3 \mathrm{~B}^{22,23}$. Portanto, é natural que na ausência das DNMT1, as células progressivamente, após as replicações celulares, venham a perder o radical metil. Este processo é chamado de desmetilação passiva ${ }^{24}$.

\section{Alterações na cromatina por histonas}

A afinidade química entre histonas e DNA se deve ao fato de possuírem de maneira geral, cargas opostas. Sendo o DNA carregado negativamente e as histonas carregadas positivamente ${ }^{25}$. A estrutura de DNA condensada por histonas impede a ligação do fator de transcrição ao DNA, este é um evento mediado pelas HDACs. Para que haja a reversão deste complexo, e haja a possibilidade reativação das funções genéticas, é importante a interferência de enzimas que modificam essas interações entre as histonas e o DNA. Uma classe de tais proteínas, a histona acetiltransferase (HAT), serve para acetilar aminoácidos selecionados nas caudas das histonas salientes, mais comumente a histona $3(\mathrm{H} 3)$ ou a histona $4(\mathrm{H} 4)$.

A acetilação de um resíduo de lisina $(K)$ em H3 serve para neutralizar a histona carregada positivamente, relaxando a relação histona-DNA e permitindo a ligação do fator de transcrição ao DNA. Assim, a acetilação de H3K9 (H3K9ac) serve como um marcador de transcrição de genes ativos ${ }^{25}$.

\section{EPIGENÉTICA, AMBIENTE E OCITOCINA}

\section{Estudos com humanos}

Quanto aos mecanismos bioquímicos que modulam comportamento humano, diversos ensaios vêm demonstrando que a epigenética é um elo entre o ambiente, o desenvolvimento de padrões de comportamento e a transgeracionalidade destes ${ }^{26}$. A fim de comprovar as hipóteses de que o ambiente de cuidados maternos interfere de modo a inibir ou estimular a expressão de neuromoduladores e/ou seus receptores, ou até mesmo para que se tenha uma estimativa correlacional destas expressões em outros tecidos mais acessíveis, se faz importante a análise de tecido cerebral. A dificuldade de se obter amostras de tecido cerebral em humanos expostos a meios específicos é evidente. Dentre as alternativas disponíveis estão a coleta de tecidos alternativos como sangue periférico, células epiteliais, ou a utilização de tecidos pós-morte. Certamente, as correlações resultantes das análises de tecidos alternativos só serão relevantes se os resultados concordarem de maneira relacional com as alterações neurofuncionais das células cerebrais.

Felizmente, evidências indiretas sugerem que os níveis de metilação do promotor do receptor de OT (OTR), medidos no epitélio bucal, podem, de fato, ser de relevância fisiológica para o comportamento ${ }^{27}$. Estudos prévios com humanos encontraram forte correlação entre os níveis de metilação do DNA cerebral e DNA de sangue periférico em relação ao sítio 3p25.3 (promotor CpG do OTR) ${ }^{28-30}$. Em um experimento com humanos diagnosticados com distúrbios do espectro autista, Jack et al., (2012) observaram através de ressonância magnética com contraste uma relação significativa entre nível de metilação do gene OTR em sangue periférico, e a atividade cerebral na junção parietal temporal e córtex cingulado anterior dorsal, duas regiões cerebrais conhecidas por controlar as funções da percepção social ${ }^{31}$.

De fato, vários estudos sobre a função da OT no espectro autista estão apresentando resultados interessantes. Em um trabalho anterior, Gregory S, et.al, 2009 coletou amostras de tecido cerebral humano congelado do giro temporal superior pós-morte de pacientes autistas com objetivo de relacionar os sintomas clínicos com a expressão de OTR. Foram identificados vários dinucleotídeos CpG com aumentos significativos independentes no estado de metilação de DNA, tanto nas células de sangue periférico quanto no córtex temporal dos pacientes ${ }^{28}$. Estes resultados mostram que a regulação epigenética de OTR pode ser um fator importante no desenvolvimento do autismo.

A esquizofrenia é um transtorno com forte relação a condições ambientais adversas durante o desenvolvimento, tais como o estresse perinatal, apresentando sintomas negativos no qual incluem desordem social ${ }^{32,33}$. Receptores OT foram localizados em diversas regiões associadas a esquizofrenia, como sub-regiões dos núcleos da base, núcleo central da amígdala, substância negra e núcleo septal lateral ${ }^{34}$. 
Em seu estudo, Rubin LH, et. al, 2015, concluiu que os níveis de metilação do sítio promotor de OTR-934 foi maior em pacientes esquizofrênicos com défitis da cognição social em comparação com pacientes bipolares ${ }^{35}$. Em uma revisão relativamente recente, Shilling e Feifel (2015) reuniram achados clínicos da aplicação e o papel da OT nas manifestações dos sintomas positivos, negativos e de déficit cognitivo na esquizofrenia. A conclusão sugere que a administração de OT exógena pode ser um importante coadjuvante no alívio dos sintomas positivos, negativos (que não são amenizados com os tratamentos atuais), e relevante melhora dos déficits cognitivos de desajuste social ${ }^{32}$.

Outros trabalhos vêm relacionando a OT com outros distúrbios psíquicos, demonstrando a importância desse neurormônio na modulação do comportamento humano. Visto que transtornos mentais são complexos, havendo ainda, subclassificações e diversos fatores envolvidos, cabe ressaltar, que estes estudos se encontram ainda no início de conclusões definitivas sobre seus respectivos funcionamentos neuroendócrinos. Para exemplificar brevemente, ainda diversas publicações são promissoras em avaliar o sistema ocitocinérgico no entendimento e controle de sintomas em outros transtornos como: Transtornos de Humor, Transtorno Depressivo Maior, Transtornos de ansiedade, Transtornos de Personalidade $^{36}$.

\section{Estudos em modelos animais}

Os estudos com humanos trazem informações importantes e são essenciais para a aplicação clínica dos resultados, porém apresentam algumas limitações. Por exemplo, no uso de modelos animais existe vantagem de induzir ambientes específicos de forma mais controlada desde antes do nascimento e depois controlar a exposição ambiental. Além disso, para estudar os mecanismos através dos quais os ambientes in útero ou pós-natal induzem diferenças neurofisiológicas e de comportamento, a grande maioria das pesquisas são realizadas utilizando modelos animais.

Em seu estudo, Baker, Maggie et al. (2017) utilizaram macacos rhesus expostos a interrupção do cuidado materno. Nessa condição, os filhotes são removidos de seus pais ao nascer e criados com outros com idade igualada para que eles se desenvolvam na ausência de influência do macaco adulto, sendo designados macacos criados por pares (PR). Os PR desenvolvem vínculos fortes com seus companheiros de idade e geralmente os usam como base para se comportar. Em contrapartida dos filhotes criados pela mãe (MR), os PR apresentam evidências de inserção insegura, níveis mais altos de ansiedade e menores níveis de exploração em novas configurações ${ }^{37}$. Os macacos expostos à adversidade precoce sob a forma de PR mostram diferenças duradouras na função e no comportamento social, aparentemente sendo mais reativos e menos capazes de se adaptarem ao estresse. Ainda neste estudo, os pesquisadores analisaram marcadores de ativação gênica H3K4me3 (trimetilação em lisina 4 na proteína histona H3) de amostras de hipocampo de macacos PR e MR, e ao comparar as amostras, foi observada uma diminuição da ligação $\mathrm{H} 3 \mathrm{~K} 4 \mathrm{me} 3$ das amostras de hipocampo nos macacos PR, com uma significante diminuição na região promotora do gene do OTR, com diminuição correspondente na expressão de mRNA de OTR ${ }^{37}$.

Já em estudos com roedores, sabe-se que as ratas geralmente têm aversão a filhotes, a menos que ela esteja no período final da gravidez ou em fase de lactação. O motivo pelo qual isso ocorre é totalmente natural, já que ratos adultos têm aversão pelo desconhecido (neofóbicos). Junto à concepção, o aumento de hormônios como o estrogênio, juntamente ao sistema ocitocinérgico no cérebro diminuem a ansiedade e induzem a expressão do comportamento materno nas ratas, colaborando para a extinção da neofobia ${ }^{38,39}$. O aumento dos efeitos ocitocinérgicos em resposta a indução de estrogênio deve-se ao estrogênio aumentar a sensibilidade do OTR para $\mathrm{OT}^{40}$. O estrogênio desencadeia uma cascata intracelular a fim de formar um complexo funcional que promove a expressão do gene da OTR ${ }^{41}$.

As fêmeas que mais respondem maternalmente aos filhotes e que apresentaram níveis aumentados de cuidados maternos, normalmente avaliados pela frequência dos atos de lamber e ajeitar os filhotes (licking/grooming - L/G), também apresentam níveis significativamente maiores de OTR na área préótica medial, no septo lateral, no núcleo central da amígdala, no núcleo paraventricular do hipotálamo e no núcleo do leito da estria terminal. Essas diferenças nos níveis de OTR estão funcionalmente relacionadas com o comportamento materno ${ }^{40,42}$.

O estrogênio em níveis aumentados no período fértil estimula a transcrição de mRNA dos OTR e aumenta a sensibilidade da OT aos OTR do SNC de ratas. Essa mecânica neurofisiológica reforça a função da OT como um potente hormônio de efeito ansiolítico das interações sociais, já que neste período, para que haja a aproximação do acasalamento, a ansiedade com o desconhecido deve ser reduzida. A OT juntamente o estrogênio atuam em conjunto para estimular o comportamento sexual e materno, visto que os efeitos da ocitocina sobre o comportamento materno são ausentes quando o estrogênio também é ausente ${ }^{40}$. 


\section{A NEGLIGÊNCIA MATERNA E O COMPROMETIMENTO DO DESENVOLVIMENTO}

A negligência materna é definida como a negação de prover as necessidades intrínsecas de uma criança ${ }^{43}$. Este fator é visto como um importante desencadeante de diversos transtornos de consequências comportamentais, sociais e cognitivas que se manifestam desde a infância até a fase adulta ${ }^{44,45}$. A comunicação de diversos sistemas sensoriais, perceptivos, afetivos e cognitivos desempenha um papel crítico no aprendizado social e no desenvolvimento cognitivo de seres humanos ${ }^{46}$. Por outro lado, se ocorre negligência nas tarefas de cuidado por parte dos pais, sendo estas negadas ou insuficientes, o aprendizado do comportamento social da criança tende a ser prejudicado ${ }^{47}$.

A negligência infantil pode ser diferenciada em física e emocional. A negligência física consiste na falta de prover alimentação adequada, higiene, cuidados em saúde, educação, vestuário próprio ao clima, ou a suscetibilidade da criança a riscos, estando esta, geralmente associada à desvantagem socioeconômica ou pobreza extrema ${ }^{48}$. Já na negligência emocional, ou psicológica, os pais podem, muitas vezes, suprir em excesso as necessidades físicas e desprover as necessidades emocionais, como se define pela desvalorização, abuso, privação do afeto e inabilidade de reconhecer as necessidades emocionais da criança ${ }^{48}$. Grande parte das crianças negligenciadas convivem com a combinação de negligência física e emocional. Na maioria das vezes, o desajuste psíquico dos cuidadores, seja por abuso de substâncias ou doenças mentais, desorganiza as devidas respostas maternas de cuidado. As noções de responsabilidade com as necessidades da criança são distorcidas, tornando os cuidados físicos e emocionais prejudicados ou ausentes ${ }^{8}$.

A longo prazo, os maus-tratos psicológicos comprometem o desenvolvimento social e emocional da criança, colaborando para o desenvolvimento de sintomas como: baixa autoestima ou autoconceito negativo, instabilidade ou desajuste emocional, redução da capacidade de resposta emocional, incapacidade de se tornar independente, dificuldade de confiar nos outros, inabilidade social, isolamento, depressão, suscetibilidade ao vício, encoprese e enurese, melancolia, depressão, promiscuidade, suicídio e homicídio ${ }^{49,50}$. Ainda, o cuidado materno negligente e/ou abusivo é notado como um comportamento herdado, de continuidade transgeracional ${ }^{51,52}$. Estimativas indicam que até $70 \%$ dos pais abusivos foram abusados na infância, ao mesmo tempo que 20 a $30 \%$ dos bebês abusados provavelmente se tornarão abusadores ${ }^{51,53}$.
A avaliação da transmissão do comportamento de características negligentes em humanos esbarra em alguns desafios éticos e dificuldades em encontrar grupos inseridos no mesmo contexto. Por esse motivo, modelos roedores são amplamente utilizados em estudos relacionados ao cuidado materno por apresentarem padrões de comportamento que definem os níveis do cuidado.

No ambiente controlado de laboratório é possível induzir situações que seriam equivalentes ao cuidado materno negligente. Um dos principais padrões de cuidado materno avaliados na literatura são a frequência de licking/grooming (L/G), que consistem no ato de lamber e ajeitar os filhotes, e a amamentação arqueada, que se caracteriza pelo dorso em postura arqueada durante a amamentação, este comportamento expõe as mamas e facilita a ejeção do leite ${ }^{54}$.

Em estudos conduzidos utilizando roedores, o comportamento materno foi transmitido através das gerações; ou seja, filhotes fêmeas que recebem cuidados maternos intensivos demonstram dar sequência nesse comportamento na vida adulta ${ }^{53,55,56}$. Porém, este padrão comportamental parece ser modulado pelo ambiente tanto no período pré-natal quanto no pós-parto. Ratas com altos níveis de L/G expostas ao stress na última semana de gestação (stress pré-natal) apresentam diminuição significativa do comportamento de L/G. No período pós-parto, o desmame precoce (stress pós-parto) interfere de maneira negativa na manifestação do cuidado materno normal está associada a níveis mais baixos de L/G e amamentação em postura arqueada. A redução do comportamento materno causada pelo desmame precoce colabora para que estes filhotes se tornem camundongos mais ansiosos e agressivos ${ }^{55}$.

O desenvolvimento e a transmissão do padrão comportamental materno para a prole já foram comprovados previamente. Filhas de mães com elevada frequência de $L / G$ apresentam o mesmo padrão comportamental com suas ninhadas ${ }^{40,57}$. Em um estudo de Champagne e Frances (2008), fêmeas com elevada frequência de L/G tiveram suas proles trocadas com as de fêmeas com baixa frequência de $L / G$. As fêmeas nascidas de ratas com L/G baixo posteriormente adotadas por mães com $L / G$ alto exibiram níveis elevados de $L / G$ em relação aos seus próprios filhotes, enquanto que as fêmeas nascidas de mães de alto $L / G$ e depois cuidadas por fêmeas com níveis baixos de $L / G$ deram continuidade quanto ao baixo comportamento de cuidado com sua própria prole. Portanto, a troca de ninhadas colabora para evidenciar que o ambiente de cuidado materno, principalmente nos primeiros dias de vida da prole, de fato induz mecanismos epigenéticos que alteram a expressão de neuromoduladores do comportamento ${ }^{53}$. 


\section{CONCLUSÃO}

Os mecanismos epigenéticos possuem suma importância de ordem evolutiva, a fim de integrar variações ambientais, sejam protetoras ou adversas, à padrões de comportamento. Muitos destes padrões, como o abuso e a negligência infantil, são fortes preditores do desenvolvimento de diversas psicopatologias que têm em comum sintomas de déficit na capacidade de se relacionar socialmente como: a esquizofrenia, o transtorno esquizoafetivo e o autismo. Níveis de OT abaixo dos controles foram encontrados no LCR destes pacientes. Em modelos animais, a qualidade do comportamento materno parece estar ligada aos níveis de OT e seus receptores.

O sistema ocitocinérgico tem um papel importante na estimulação do afeto, confiança, cuidado materno e controle da ansiedade. Através dos estudos referidos, percebemos a conexão entre os padrões comportamentais negligentes, a transgeracionalidade destes comportamentos e o fato destes comportamentos serem fatores de risco para o desenvolvimento de psicopatologias que envolvem desordem social e baixo cuidado materno. Inclusive, o sistema ocitocinérgico induz padrões comportamentais muito específicos e seus genes parecem estar menos ativos quando estes padrões estão ausentes. O ambiente hostil de abuso e negligência na infância, a inativação epigenética dos genes do sistema ocitocina, o desenvolvimento posterior de desordens psicológicas sociais, e a transgeracionalidade destes padrões demonstram alguma correlação.

Tentativas de utilizar ocitocina exógena obtiveram resultados em estimular o comportamento social afetivo em cobaias. Porém, em humanos a OT exógena demonstra efeitos benéficos sob circunstâncias específicas, onde contextos ambientais individuais parecem interferir. O potencial terapêutico da OT no controle das desordens sociais parece promissor, mas requer que estudos futuros considerem a complexidade e as nuances contextuais de cada desordem.

\section{Financiamento}

Os autores declaram que não obtiveram auxílio de nenhuma fonte de financiamento.

\section{Conflitos de Interesse}

Os autores declaram não possuírem conflitos de interesse.

\section{Referências}

1. Chaves DI. Efeito da ocitocina sobre a 6. Vassoler FM, Sadri-Vakili G. ansiedade experimental induzida em voluntários saudáveis [dissertação]. Ribeirão Preto: Universidade de São Paulo; 2007.

2. Dacome OA, Garcia RF. Oxytocin's modulating effect on pleasure. Saúde e Pesqui [online]. 2008 [citado 2020 jan 6];1(2):193-200. Disponível em: http://periodicos.unicesumar. edu.br/index.php/saudpesq/article/ viewFile/751/608

3. Neigh GN, Gillespie CF, Nemeroff CB The neurobiological toll of child abuse and neglect. Trauma Violence Abuse. 2009;10(4):389-410.

4. Kessler R, Davis C, Kendler K. Childhood adversity and adult psychiatric disorder in the US National Comorbidity Survey. Psychol Med. 1997;27:1101-19.

5. Nagy C, Turecki G. Transgenerational epigenetic inheritance: an open discussion. Epigenomics. 2015;7:781-90 does it mean? Horm Behav. Mechanisms of transgenerational inheritance of addictive-like behaviors. Neurosci. [online] 2014 [citado 2013 ago 3];264:198-206. Disponível em: https://www.ncbi.nlm.nih.gov/ pubmed/23920159

7. Churchland PS, Winkielman P. Modulating social behavior with oxytocin: how does it work? What 2012;61:392-9. http://dx.doi. org/10.1016/j.yhbeh.2011.12.003.

8. Strathearn L. Maternal neglect: oxytocin, dopamine and the neurobiology of attachment. J Neuroendocrinol. 2011;23(11):1054-65.

9. Winslow JT, Noble PL, Lyons CK, Sterk SM, Insel TR. Rearing effects on cerebrospinal fluid oxytocin concentration and social buffering in rhesus monkeys. Neuropsychopharmacology. 2003;28(5):910-8.

10. Heim C, Young LJ, Newport DJ, Mletzko T, Miller AH, Nemeroff CB. Lower CSF oxytocin concentrations in women with a history of childhood abuse. J Mol Psychiatry. 2009;14(10):954-8. http://dx.doi. org/10.1038/mp.2008.112.

11. Muller HR, Prado KB. Epigenética: um novo campo da genética. Rubs. [online] 2008 [citado 2020 jan 6];(3):61-9. Disponível em: http:// www.colegiogregormendel.com.br/ gm_colegio/pdf/2012/textos/3ano/ biologia/8.pdf

12. D'Alessio AC, Szyf M. Epigenetic tête-à-tête: the bilateral relationship between chromatin modifications and DNA methylation. Biochem Cell Biol. 2006;84(4):463-6. https://doi. org/10.1139/o06-090.

13. Liu L, Li Y, Tollefsbol TO. Geneenvironment interactions and epigenetic basis of human diseases. Curr Issues Mol Biol. [online] 2008;10(1-2):25-36. Disponível em: https://www.ncbi.nlm.nih.gov/ pubmed/18525104

14. Schierding W, Cutfield WS, O'Sullivan $\mathrm{JM}$. The missing story behind Genome Wide Association Studies: single 
nucleotide polymorphisms in gene deserts have a story to tell. Front Genet. 2014;5:1-7.

15. Feinberg P. Cancer epigenetics takes center stage. Proc Natl Acad Sci U S A. $2001 ; 98(2): 392-4$.

16. Strahl BD, Allis CD. The language of covalent histone modifications. Nature. 2000;403(6765):41-5.

17. Jang HS, Shin WJ, Lee JE, Do JT. CpG and non-CpG methylation in epigenetic gene regulation and brain function. Genes (Basel). 2017;8(6):2-20.

18. Garinis GA, Patrinos GP, Spanakis NE, Menounos PG. DNA hypermethylation: when tumour suppressor genes go silent. Hum Genet. 2002;111(2):115-27.

19. Francis N, Oliveira P, Planello AC, Andia DC, Pardo APS. Metilação de DNA e Câncer. Rev Bras Cancerol. 2010;56(4):493-9.

20. $\mathrm{Ng} \mathrm{HH}$, Bird A. DNA methylation and chromatin modification. Curr Opin Genet Dev. 1999;9(2):158-63.

21. Jin B, Robertson KD. DNA methyltransferases, DNA damage repair, and cancer. Adv Exp Med Biol. 2013;754:3-29.

22. Jin B, Li Y, Robertson KD. DNA methylation: superior or subordinate in the epigenetic hierarchy? Genes Cancer. [online] 2011;2(6):607-17. Disponível em: https://www.ncbi.nlm. nih.gov/pubmed/21941617

23. Valladares-Salgado $A$, SuárezSánchez F, Burguete-García Al, Cruz M. Epigenetics of childhood obesity and diabetes. Rev Med Inst Mex Seguro Soc. [online] 2014 [cited 2019 maio 1];52(suppl. 1):S88-93. Disponível em: http://www.ncbi.nlm. nih.gov/pubmed/24866314

24. He S, Sun H, Lin L, Zhang Y, Chen $J$, Liang L, et al. Passive DNA demethylation preferentially upregulates pluripotency-related genes and facilitates the generation of induced pluripotent stem cells. $J$ Biol Chem. 2017;292(45):18542-55.

25. Fish EW, Shahrokh D, Bagot R, Caldji C, Bredy T, Szyf M, et al. Epigenetic programming of stress responses through variations in maternal care. Ann N Y Acad Sci. 2004;1036:167-80.
26. Cohen P, Brown J, Smaile E. Child abuse and neglect and the development of mental disorders in the general population. Dev Psychopathol. 2001;13(4):981-99.

27. Smith AK, Kilaru V, Klengel T, Mercer KB, Bradley B, Conneely KN, et al. DNA extracted from saliva for methylation studies of psychiatric traits: evidence tissue specificity and relatedness to brain. Am J Med Genet Part B Neuropsychiatr Genet. 2015;168(1):36-44.

28. Gregory SG, Connelly JJ, Towers AJ, Johnson J, Biscocho D, Markunas $\mathrm{CA}$, et al. Genomic and epigenetic evidence for oxytocin receptor deficiency in autism. BMC Med. 2009;7:1-13.

29. Liu X, Kawamura Y, Shimada T, Otowa T, Koishi S, Sugiyama T, et al. Association of the oxytocin receptor (OXTR) gene polymorphisms with autism spectrum disorder (ASD) in the Japanese population. J Hum Genet. 2010;55:137-41

30. Ylisaukko-oja T, Alarcón M, Cantor RM, Auranen M, Vanhala R, Kempas $E$, et al. Search for autism loci by combined analysis of Autism Genetic Resource Exchange and Finnish families. Ann Neurol. 2006;59(1):14555. https://doi.org/10.1002/ana.20722.

31. Jack A, Connelly JJ, Morris JP. DNA methylation of the oxytocin receptor gene predicts neural response to ambiguous social stimuli. Front Hum Neurosci. [online] 2012 [citado 2017 nov 30];6:280. Disponível em: http://www.ncbi.nlm.nih.gov/ pubmed/23087634

32. Shilling PD, Feifel D. Potential of Oxytocin in the Treatment of Schizophrenia. CNS Drugs. [online] 2016 [citado 2020 jan 6];30(3):193208. Disponível em: https://www.ncbi. nlm.nih.gov/pubmed/26895254

33. Joseph B, Narayanaswamy JC, Venkatasubramanian G. Insight in schizophrenia: relationship to positive, negative and neurocognitive dimensions. Indian J Psychol Med. [online] 2015;37(1):5-11. Disponível em: https://www.ncbi.nlm.nih.gov/ pubmed/25722504

34. Loup F, Tribollet E, Dubois-Dauphin M, Dreifuss JJ. Localization of highaffinity binding sites for oxytocin and vasopressin in the human brain: an autoradiographic study. Brain Res. 1991;555(2):220-32.
35. Rubin LH, Connelly JJ, Reilly JL, Carter CS, Drogos LL, PournajafiNazarloo H, et al. Sex and diagnosis specific associations between DNA methylation of the oxytocin receptor gene with emotion processing and temporal-limbic and prefrontal brain volumes in psychotic disorders. Biol Psychiatry Cogn Neurosci Neuroimaging. [online] 2016 [citado 2015 nov 9];1(2):141-51. Disponível em: https://www.ncbi.nlm.nih.gov/ pubmed/26977453

36. Cochran DM, Fallon D, Hill M, Frazier JA. The role of oxytocin in psychiatric disorders: a review of biological and therapeutic research findings. Harv Rev Psychiatry. [online] 2013;21(5):219-47. Disponível em: https://www.ncbi.nlm.nih.gov/ pubmed/24651556

37. Baker M, Lindell SG, Driscoll CA, Zhou Z, Yuan Q, Schwandt ML, et al. Early rearing history influences oxytocin receptor epigenetic regulation in rhesus macaques. Proc Natl Acad Sci U S A. [online] 2017 [citado 2017 out 16];114(44):11769-74. Disponível em: https://www.ncbi.nlm.nih.gov/ pubmed/29078292

38. Giordano AL, Siegel HI, Rosenblatt JS. Nuclear estrogen receptor binding in the preoptic area and hypothalamus of pregnancy-terminated rats: correlation with the onset of maternal behavior. Neuroendocrinology. 1989;50(3):248-58.

39. Pedersen CA. Oxytocin control of maternal behavior regulation by sex steroids and offspring stimulia. Ann N Y Acad Sci. 1997;807(1):126-45. https://doi. org/10.1111/j.1749-6632.1997. tb51916.x.

40. Champagne F, Diorio J, Sharma S, Meaney MJ. Naturally occurring variations in maternal behavior in the rat are associated with differences in estrogen-inducible central oxytocin receptors. Proc Natl Acad Sci. [online] 2001;98(22):12736-41. Disponível em: http://www.pnas.org/ content/98/22/12736

41. Sharma D, Handa RJ, Uht RM. The ER $\beta$ ligand $5 \alpha$-androstane, $3 \beta, 17 \beta$ diol ( $3 \beta$-diol) regulates hypothalamic oxytocin (Oxt) gene expression. Endocrinology. [online] 2012 [citado 2012 mar 20];153(5):2353-61. Disponível em: https://www.ncbi.nlm. nih.gov/pubmed/22434086 
42. Van Leengoed E, Kerker E, Swanson $\mathrm{HH}$. Inhibition of post-partum maternal behaviour in the rat by injecting an oxytocin antagonist into the cerebral ventricles. J Endocrinol. 1987;112(2):275-82.

43. Sedlak A, Broadhurst D. A history of the national incidence study of child abuse and neglect. Special studies and strategy planning: national incidence study of child abuse and neglect. [online] Washington, DC: U.S. Department of Health and Human Services; 2001. Disponível em: https:// www.nis4.org/NIS_History.pdf

44. Cahill LT, Kaminer RK, Johnson PG. Developmental, cognitive, and behavioral sequelae of child abuse. Child Adolesc Psychiatr Clin N Am. [online] 1999 [citado 2019 abr 11];8(4):827-43. Disponível em: https://www.sciencedirect. com/science/article/abs/pii/ S1056499318301561

45. Spratt EG, Friedenberg S, LaRosa A, Bellis MD, Macias MM, Summer AP, et al. The effects of early neglect on cognitive, language, and behavioral functioning in childhood. Psychology. 2012;3(2):175-82.

46. Fries ABW, Ziegler TE, Kurian JR, Jacoris $\mathrm{S}$, Pollak SD. From the cover: early experience in humans is associated with changes in neuropeptides critical for regulating social behavior. Proc Natl Acad Sci. [online] 2005;102(47):17237-40. Disponível em: http://www.pnas.org/ cgi/doi/10.1073/pnas.0504767102
47. O'Leary KD. Physical aggression between spouses: a social learning perspective. Handbook of Family Violence. New York: Springer;1988. p. $31-55$.

48. Dubowitz H. Neglect in children. Pediatr Ann. [online] 2013 [citado 2020 jan 6];42(4):73-7. Disponível em: https://www.ncbi.nlm.nih.gov/ pubmed/23556521

49. Fergusson DM, Horwood LJ, Lynskey MT. Childhood sexual abuse and psychiatric disorder in young adulthood: II. Psychiatric outcomes of childhood sexual abuse. J Am Acad Child Adolesc Psychiatry. 1996;35(10):1365-74. http://dx.doi. org/10.1097/00004583-19961000000024.

50. Silverman AB, Reinherz HZ, Giaconia RM. The long-term sequelae of child and adolescent abuse: a longitudinal community study. Child Abuse Negl. [online] 1996 [citado 2020 jan 6];20(8):709-23. Disponível em: http:// www.sciencedirect.com/science/ article/pii/0145213496000592

51. Chapman DA, Scott KG. The impact of maternal intergenerational risk factors on adverse developmental outcomes. Dev Rev. [online] 2001;21(3):30525. Disponível em: http://www. sciencedirect.com/science/article/pii/ S0273229700905239

52. Benoit D, Parker KCH. Stability and transmission of attachment across three generations. Child Dev. 1994;65(5):1444-56. https:// doi.org/10.1111/j.1467-8624.1994. tb00828.x.
53. Champagne FA. Epigenetic mechanisms and the transgenerational effects of maternal care. Front Neuroendocrinol. [Internet]. 2008 [citado $2008 \mathrm{mar}$ 28];29(3):386-97. Disponível em: https://www.ncbi.nlm.nih.gov/ pubmed/18462782

54. Stern JM, Johnson SK. Ventral somatosensory determinants of nursing behavior in Norway rats. I. Effects of variations in the quality and quantity of pup stimuli. Physiol Behav. [online] 1990;47(5):9931011. Disponível em: http://www. sciencedirect.com/science/article/ pii/003193849090026Z

55. Kikusui T, Isaka Y, Mori Y. Early weaning deprives mouse pups of maternal care and decreases their maternal behavior in adulthood. Behav Brain Res. [online] 2005;162(2):2006. Disponível em: http://www. sciencedirect.com/science/article/pii/ S0166432805001051

56. Champagne FA, Francis DD, Mar A, Meaney MJ. Variations in maternal care in the rat as a mediating influence for the effects of environment on development. Physiol Behav. [online] 2003;79(3):359-71. Disponível em: http://www.sciencedirect.com/science/ article/pii/S0031938403001495

57. Francis D, Diorio J, Liu D, J Meaney $M$. Nongenomic transmission across generations of maternal behavior and stress responses in the rat. Science. 1999;286:1155-58. 